\title{
Biopsychosocial needs of survivors of testicular cancer and evidence of validation of a brief scale
}

\section{Necessidades biopsicossociais de sobreviventes de câncer de testículo e evidência de validação de escala breve}

\author{
Maria Fernanda Marcusso MANHÃES' (D) 0000-0001-9623-8950 \\ Getulio Yuzo OKUMA' (D) 0000-0001-6436-2607 \\ Renata Nunes PEDRAS ${ }^{1}$ (D) 0000-0003-2716-0664 \\ Edvane Birelo Lopes DE DOMENICO² (D) 0000-0001-7455-1727 \\ Cristiane Decat BERGEROT² (iD 0000-0003-0037-0303
}

\begin{abstract}
The favorable prognosis of testicular cancer does not minimize immediate and late biopsychosocial implications. This study sought to determine these needs, and to evaluate the evidence of validation of a brief and specific scale for this population. A sample of 29 survivors of testicular cancer $(n=29)$ was assessed for distress (Distress Thermometer), anxiety and depression (Hospital Anxiety and Depression Scale), quality of life and cognitive impairment (Functional Assessment of Chronic Illness Therapy-General and Cognitive Function), and specific needs (Cancer Assessment for Young Adults-Testicular). It was observed a high prevalence of distress $(41.4 \%)$, a low prevalence of anxiety (6.9\%) and depression (6.9\%), and a moderate impact on quality of life and cognition. Self-image and sexual function were the most preponderant problems. The evidence of validation of Cancer Assessment for Young Adults-Testicular12 was verified in the psychometric analysis. Notably, biopsychosocial needs identified on global scales, and particularly in Cancer Assessment for Young Adults-Testicular12, assisted in understanding these specificities and in therapeutic planning.
\end{abstract}

Keywords: Anxiety; Depression; Distress; Quality of life; Testicular neoplasms.

$\sim r$

${ }^{1}$ Universidade Federal de São Paulo, Hospital São Paulo, Programa de Residência Multiprofissional em Oncologia. São Paulo, SP, Brasil.

${ }^{2}$ Universidade Federal de São Paulo, Escola Paulista de Enfermagem, Departamento de Enfermagem Clínica e Cirúrgica. São Paulo, SP, Brasil.

${ }^{3}$ City of Hope Comprehensive Cancer Center, Department of Medical Oncology \& Experimental Therapeutics. 1500 Duarte Rd, 91010 , Duarte, California, United States. Correspondência para/Correspondence to: C.D. BERGEROT. E-mail: <crisbergerot@gmail.com>.

$\boldsymbol{\nabla} \nabla \boldsymbol{V}$

Como citar este artigo/How to cite this article

Manhães, M. F. M., Okuma, G. Y., Pedras, R. N., De Domenico, E. B. L., \& Bergerot, C. D. (2019). Biopsychosocial needs of survivors of testicular cancer and evidence of validation of a brief scale. Estudos de Psicologia (Campinas), 36, e180075. http://dx.doi. org/10.1590/1982-0275201936e180075 


\section{Resumo}

O prognóstico favorável do câncer de testículo não minimiza as implicações biopsicossociais imediatas e tardias. Este estudo objetiva determinar essas necessidades e avaliar a evidência de validação de escala breve e específica para essa população. Uma amostra de 29 pacientes sobreviventes de câncer de testículo foi avaliada quanto ao distress (Termômetro de Distress), ansiedade e depressão (Escala de Ansiedade e Depressão), qualidade de vida e prejuízo cognitivo (Functional Assessment of Chronic Illness Therapy-General e Cognitive Function) e demandas especificas (Cancer Assessment for Young Adults-Testicular12). Observou-se alta prevalência de distress (41,4\%), baixa prevalência de ansiedade (6,9\%) e depressão (6,9\%) e moderado impacto na qualidade de vida e cognição. Autoimagem e função sexual foram os problemas mais preponderantes. A evidência de validação do Cancer Assessment for Young Adults-Testicular12 foi constatada na avaliação psicométrica. Notavelmente, as necessidades biopsicossociais identificadas nas escalas globais e, particularmente no Cancer Assessment for Young Adults-Testicular12, auxiliaram no entendimento dessas especificidades e no planejamento terapêutico.

Palavras-chave: Ansiedade; Depressão; Distress; Qualidade de vida; Neoplasias testiculares.

Testicular cancer accounts for $1 \%$ of neoplasms in men (Cappuccio et al., 2018). Although rare, it is the solid tumor with the highest incidence in adolescents and young adults between 15 and 35 years old (Smith et al., 2013). It is expected that this diagnosis will have a significant impact on the patient's physical, psychological and social well-being, with potential family, social, professional and financial repercussions (Carpentier, Fortenberry, Ott, Brames, \& Einhorn, 2011). However, it is considered a neoplasm with an excellent prognosis; the five-year survival rate is $98 \%$ (National Comprehensive Cancer Network, 2018).

Among the treatment modalities, the surgical removal of the testicle(s), unilateral or radical orchiectomy, is the first option (National Comprehensive Cancer Network, 2018); when the pathological diagnosis is defined (seminoma or non-seminoma), as well as the disease stage and the need for an additional treatment with platinum-based chemotherapy and/or radiotherapy. Orchiectomy can result in lasting feelings of loss, discomfort or shame (Skoogh et al., 2011). Some patients, for example, report feeling less attractive or questioning their own sexuality (Fossa et al., 2003). In addition, chemotherapy is associated with short-and long-term adverse events, including cardiovascular problems, renal failure, neuropathy, fatigue, and cognitive impairments, the most commonly identified (Abouassaly et al., 2011; Shen et al., 2016; Travis et al., 2010). There are also issues related to fertility and sexual function (Abouassaly et al., 2011); a quarter of these patients reported decreased libido and $43 \%$ reported decreased in sexual activity (Rossen, Pedersen, Zachariae, \& von der Maase, 2012).

The sequelae of treatments may potentiate the appearance of biopsychosocial problems, making these patients more susceptible to emotional distress (Vehling et al., 2016). The fear of recurrence was classified as one of the most relevant and long-lasting (present even after 10 years since diagnosis), commonly associated with intrusive thoughts, stress and worsening of physical well-being (Smith et al., 2018). Further, there are feeling of isolation, existential suffering, and feelings of vulnerability (Smith et al., 2018; Travis et al., 2010). There are also decrease or loss of reproductive capacity and psychosocial factors related to body image and the ability to establish and maintain relationships (Carpentier et al., 2011; Rossen et al., 2012). However, the prevalence of symptoms of anxiety and depression is close to that of the general population, and is lower than that reported for other types of cancer (Smith et al., 2018; Vehling et al., 2016).

Because of these biological and psychosocial characteristics being common to the age range of patients with this type of cancer (adolescents and young adults), different assessment and intervention strategies have been studied and developed (Hoyt, Cano, Saigal, \& Stanton, 2013). Recently, a conceptual

2 model for these patients was proposed, and a scale was developed based on this conceptual framework 
domains - physical, sexual, intrapersonal, cognitive-emotional, social, educational-vocational and spiritual (Cancer Assessment for Young Adults for men with testicular cancer; CAYA-T) (Hoyt et al., 2013). However, despite the relevance of this theme, in Brazil there is a gap in the knowledge about prevalent and specific needs of this group of patients, as well as translation or validation of questionnaires that can assist health care providers to target the real needs of patients with testicular cancer. Thus, the present study focused on two distinct and complementary objectives: 1) to determine the main biopsychosocial needs reported by survivors of testicular cancer and 2) to translate and to evaluate the evidence of validation of a brief version of the CAYA-T scale.

\section{Method}

This is a cross-sectional and quantitative study performed in a public hospital, located in São Paulo, Brazil. The research project was submitted and approved by the Ethics and Research Committee of the institution, under the protocol n 142781/2017. The data was collected from September, 2016 to November, 2017, at the Oncology clinic, in the waiting room for follow-up appointments with oncologists.

\section{Participants}

To compose the sample, the number of patients in follow-up was identified. Patients over 18 years of age, survivors of testicular cancer, in follow-up and who agreed to participate in this study were included. Those with a psychiatric disorder and/or baseline cognitive deficit recorded in their medical records, as well as those who withdrawn their consent during the assessment were excluded.

\section{Measures}

Sociodemographic and Clinical Questionnaire: composed of seven questions that identified age, gender, race, marital status, educational level, income and religion. In addition, six items were collected from patients' medical records, including cancer diagnosis, disease stage, date of diagnosis, current treatment, type and treatment phase.

Distress Thermometer(DT): scale proposed by the National Comprehensive Cancer Network (Holland et al., 2013), translated and validated into Portuguese (Decat, Araujo, \& Laros, 2009). This is a standard scale to assess level of distress in eleven points, ranging from 0 (no distress) to 10 (extreme distress). A score greater or equal to 4 is an indicative of moderate to severe distress (Decat et al., 2009; Holland et al., 2013). Through this scale, it is possible to identify the main problems associated with distress in a list of 35 items, subdivided into practical, family, emotional, spiritual and physical domains.

Hospital Anxiety and Depression Scale (HADS): translated and validated by Botega, Bio, Zomignani, Garcia Jr., and Pereira (1995). Fourteen items assess symptoms of anxiety and depression (seven items for each subscale; score ranging from 0 to 21). In the anxiety subscale (HADS-A), a score greater than or equal to 8 is an indicative of moderate to severe symptoms and in the depression subscale (HADS-D) it is considered the score greater than or equal to 9 (Botega et al. 1995).

Functional Assessment of Cancer Treatment - General(FACT-G): is a global scale for assessing patients with cancer regarding their quality of life; translated and validated into Portuguese by Arnold et al. (2000). It consists of 27 items that measure physical (7 items; score ranging from 0 to 28), social/family (7 items; 
score ranging from 0 to 28), emotional (6 items; score ranging from 0 to 24) and functional (7 items; score ranging from 0 to 28) well-beings. Higher scores on the global scale and its subscales are good indicators of quality of life (Arnold et al., 2000). To interpret the results, the normative study of this scale will be used (Brucker, Yost, Cashy, Webster, \& Cella, 2005).

Functional Assessment of Cancer Treatment - Cognitive function (FACT-Cog): This is a reference scale for assessing cognitive impairments due to chemotherapy (Wagner, Sweet, Butt, Lai, \& Cella, 2009). Perceived cognitive impairments (20 items; score ranging from 0 to 80 ), comments from others (4 items; score ranging from 0 to 16), perceived cognitive abilities (9 items; score ranging from 0 to 36) and impact on quality of life (4 items; score ranging from 0 to 16). Higher scores indicate lower cognitive impairments.

Cancer Assessment for Young Adults - Testicular, brief version (CAYA-T): developed by Hoyt et al. (2013) for biopsychosocial assessment of patients with testicular cancer, includes 90 items in a 3-point Likert scale ( 0 , none of the time to 2 , much or most of the time) which assess 17 domains: physical (6 items), sexual confidence ( 3 items), sexual functioning ( 5 items), body image strength ( 7 items), positive masculine self-image (7 items), positive adult self-image (1 item), cognitive-emotional regulation (14 items), disclosure ability (7 items), relationship maintenance (6 items), social connectedness (5 item), healthcare confidence (8 items), goal navigation ( 7 items), goal facility ( 5 items), financial maintenance ( 1 item), recreational pursuit ( 1 item), spiritual stability ( 1 item) and finding meaning (6 items). Lower scores indicate areas of greatest vulnerability. The authors emphasize that this scale can be used in a flexible way, being possible to use only some subscales, or even to adapt this scale to the characteristics of each service (Hoyt et al., 2013). Based on this premise and on domains proposed in the conceptual model of Hoyt et al. (2013), 29 items were selected to compose the specific evaluation of testicular patients in this study: physical (1 item), sexual confidence ( 3 items), sexual functioning ( 2 items), body image strength ( 1 items), positive masculine self-image ( 2 items), positive adult self-image ( 1 item), cognitive-emotional regulation ( 7 items), disclosure ability ( 3 items), relationship maintenance ( 2 items) and finding meaning ( 1 items). In this version, the total score varied between 0 and 58 points.

\section{Procedures}

\section{Data collection}

Eligible patients were contacted in the waiting room of the Oncology clinic. Those who were interested in participating signed an Informed Consent Form and were subsequently assessed for distress (Decat et al., 2009), anxiety and depression (Botega et al., 1995), quality of life (Arnold et al., 2000), cognitive impairments (Wagner et al., 2009) and specific needs for testicular cancer (Hoyt et al., 2013). Only instruments widely endorsed and validated for the purpose of this study were included. The application of these instruments was performed in an assisted manner, with the exception of the CAYA-T scale, which was self-answered by patients. In addition, a specific questionnaire was used to identify sociodemographic variables, and clinical information was extracted from each patient's medical record.

\section{CAYA-T adaptation}

Due to the extension of the CAYA-T scale and the existence of standardized instruments for biopsychosocial assessment of patients with cancer, we chose to select specific items described in the conceptual model of Hoyt et al. (2013), and that was not included in the global scales. At that phase, 
different specialists were approached in order to select and prioritize these items (three psychologists, two nurses, one physician and one person from outside of the health care system, in the same age range of the study population, to attest relevance to the content of each item). After reaching consensus, 33 items were selected. The authors of this scale were contacted to request an authorization to translate and to use the translated brief version. After authorization, a cross-cultural adaptation was done, and content and construct were validated. A pilot study was done to identify the understanding and clarity of items. Patients declared to have understood all 33 questions and no change in content was required. However, four items were excluded by similarity ( $n=3$, body image strength) and by cultural inadequacy ( $n=1$, positive masculine self-image).

\section{Data analysis}

To meet the first objective of this study, a descriptive analysis of sociodemographic and clinical variables was performed, using measures of central tendency and dispersion for continuous measures, and frequency for the categorical variables. The same analysis was performed for DT, HADS, FACT-G, FACT-Cog and CAYA-T, with subsequent evaluation of the association between these scales using the Chi-Square Test and the $t$-test.

For the psychometric analysis (second objective) of the brief version of the CAYA-T, internal consistency of 29 items was evaluated through the Lambda2 reliability coefficient and the mean correlation between items. Both tests were chosen based on sample size. Afterwards, an exploratory factorial analysis was conducted to obtain evidence of discriminant validity (Winter, Dodou, \& Wieringa, 2009). Only items with highest factorial loading were included in the final version of CAYA-T, called CAYA-T12 brief scale. These criteria were established based on the evidence for exploratory factorial analysis in a sample size lower than 50 individuals, in which it was considered data with high factorial loading, low number of factors and large number of variables (Ten Berge, \& Zegers, 1978). In addition, the sample size was tested by means of the Kaise-Meyer-Olkin (KMO) test. Finally, linear regression was used to assess the discriminatory power of the final version of CAYA-T12 subscales, according to the levels of distress, anxiety, depression, quality of life and cognition. All analyzes were performed using the Statistical Package for the Social Sciences (SPSS Inc., Chicago, Illinois, United States) 22.0 software for Mac.

\section{Results}

In the survey carried out in the institution's database, 73 patients registered with ICD-10 C62 (malignant testicular neoplasia) were identified. After reviewing the data on the medical record, 32 patients were excluded due to lost to follow-up or for being discharged $(n=15)$, for having scheduled an appointment after the expected time of data collection $(n=12)$, for being mistakenly registered (testicle is not the primary site; $n=2)$, for having a cognitive/psychiatric disorder $(n=2)$ and for being dead $(n=1)$. Of the 41 eligible patients, only 29 were enrolled; 10 missed the follow-up appointment and two refused to participate in this study (Figure 1).

As described in Table 1, the mean age was 31.5 years $(S D=10.4)$, most of whom declared themselves to be married (48.3\%), white Caucasian (58.6\%), employed (58.6\%), and possessing elementary school $(51.7 \%)$. A little more than half of patients were diagnosed with seminoma (51.7\%), at an early disease stage (51.7\%). However, $34.5 \%$ of them developed metastasis, being lymph nodes (17.2\%) and lung (17.2\%) the most common sites. All patients had their testicle(s) removed, and $10.3 \%$ did bilateral orchiectomy. A total 


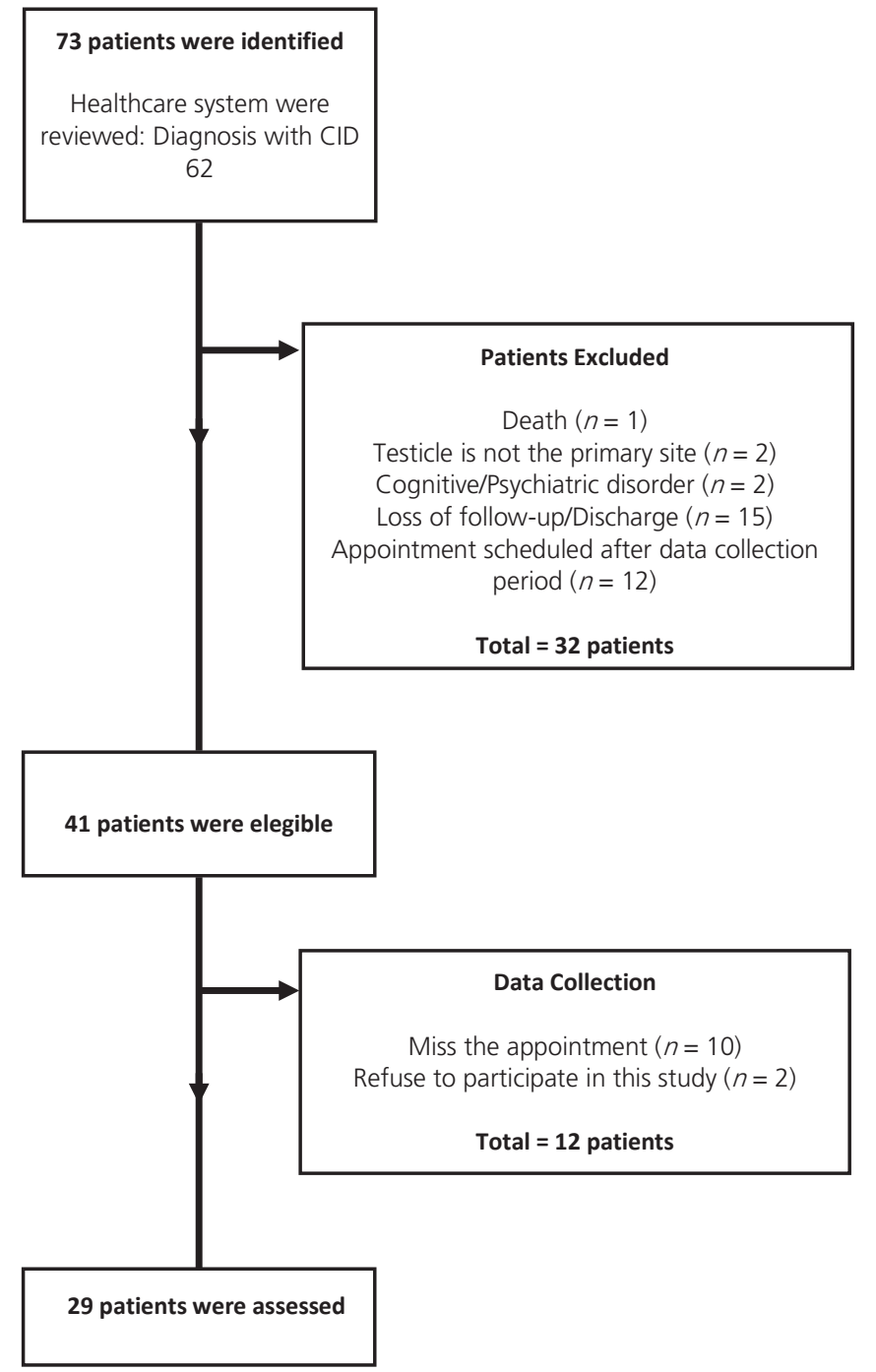

Figure 1. Flowchart of identification and selection of patients.

Table 1

Sociodemographic and clinical characteristics

\begin{tabular}{|c|c|c|c|}
\hline \multirow{2}{*}{ Characteristics } & \multicolumn{3}{|c|}{ Patients $(n=29)$} \\
\hline & $\mathrm{n}$ & $\%$ & $M(S D ; \min -\max )$ \\
\hline \multicolumn{4}{|l|}{ Age } \\
\hline$M(S D ;$ min-max $)$ & & & $31.5( \pm 10.4 ; 16-65)$ \\
\hline \multicolumn{4}{|l|}{ Marital Status (\%) } \\
\hline Single & 11 & 37.9 & \\
\hline Married & 14 & 48.3 & \\
\hline Divorced & 3 & 10.3 & \\
\hline Widowed & 1 & 3.4 & \\
\hline \multicolumn{4}{|l|}{ Education (\%) } \\
\hline No formal education & 1 & 3.4 & \\
\hline Elementary school & 7 & 24.2 & \\
\hline High school & 15 & 51.7 & \\
\hline Graduate degree & 6 & 20.7 & \\
\hline
\end{tabular}

Note: BEP: Bleomycin, Etoposide and Cisplatin; EP: Etoposide and Cisplatin; TIP: Paclitaxel, Ifosfamide and Cisplatin; VAC: Vincristine, Dactinomycin and Cyclophosphamide; M: Mean; SD: Standard Deviation. 
Table 1

Sociodemographic and clinical characteristics

\begin{tabular}{|c|c|c|c|}
\hline \multirow{2}{*}{ Characteristics } & \multicolumn{3}{|c|}{ Patients $(n=29)$} \\
\hline & $n$ & $\%$ & $M(S D ; \min -\max )$ \\
\hline \multicolumn{4}{|l|}{ Race (\%) } \\
\hline White & 17 & 58.6 & \\
\hline Black & 3 & 10.3 & \\
\hline Mulato/Pardo & 9 & 31.0 & \\
\hline \multicolumn{4}{|l|}{ Employment Status (\%) } \\
\hline Student & 2 & 6.9 & \\
\hline Employed & 17 & 58.6 & \\
\hline Unemployed & 3 & 10.3 & \\
\hline Retired & 3 & 10.3 & \\
\hline Freelance & 2 & 6.9 & \\
\hline Disability & 2 & 6.9 & \\
\hline \multicolumn{4}{|l|}{ Religion } \\
\hline Catholic & 13 & 44.8 & \\
\hline Protestantism & 9 & 31.0 & \\
\hline Spiritism & 1 & 3.4 & \\
\hline Others & 3 & 10.3 & \\
\hline No religion & 3 & 10.3 & \\
\hline \multicolumn{4}{|l|}{ Diagnosis } \\
\hline Seminoma & 15 & 51.7 & \\
\hline Nonseminoma & 14 & 48.3 & \\
\hline \multicolumn{4}{|l|}{ Disease Stage } \\
\hline 1 & 15 & 57.7 & \\
\hline$\|$ & 5 & 17.2 & \\
\hline III & 6 & 20.7 & \\
\hline Unknown & 3 & 10.3 & \\
\hline Metastasis & 10 & 34.5 & \\
\hline \multicolumn{4}{|l|}{ Year of the Diagnosis } \\
\hline 2003 to 2011 & 10 & 34.6 & \\
\hline 2012 & 5 & 17.2 & \\
\hline 2013 & 4 & 13.8 & \\
\hline 2014 & 5 & 17.2 & \\
\hline 2015 & 2 & 6.9 & \\
\hline 2016 & 2 & 6.9 & \\
\hline 2017 & 1 & 3.4 & \\
\hline \multicolumn{4}{|l|}{ Follow-up (months) } \\
\hline$M(S D ; \min -\max )$ & & & $67.5( \pm 38.5 ; 12-180)$ \\
\hline \multicolumn{4}{|c|}{ Chemotherapy (15t line, $n=21$ ) } \\
\hline BEP & 17 & 58.6 & \\
\hline EP & 1 & 3.4 & \\
\hline Carboplatin & 2 & 6.9 & \\
\hline \multicolumn{4}{|c|}{ Chemotherapy ( $2^{\text {nd }}$ line, $n=9$ ) } \\
\hline BEP & 6 & 20.7 & \\
\hline TIP & 1 & 3.4 & \\
\hline VAC & 1 & 3.4 & \\
\hline Carboplatin & 1 & 3.4 & \\
\hline Radiotherapy & 4 & 13.8 & \\
\hline
\end{tabular}

Note: BEP: Bleomycin, Etoposide and Cisplatin; EP: Etoposide and Cisplatin; TIP: Paclitaxel, Ifosfamide and Cisplatin; VAC: Vincristine, Dactinomycin and Cyclophosphamide; M: Mean; SD: Standard Deviation. 
of 21 patients received first line of chemotherapy, of these, 58.6\% received BEP (Bleomycin, Etoposide and Cisplatin), 6.9\% Carboplatin and 3.4\% EP (Etoposide and Cisplatin). Of patients who received second line of treatment (32.1\%), BEP was the most used (20.7\%). During the follow-up period, $20.7 \%$ of patients had cancer recurrence. The mean survival time was 67.5 months $(S D=38.5)$.

\section{Biopsychosocial needs of survivors of testicular cancer}

In the biopsychosocial assessment, $41.4 \%$ of patients reported moderate to severe distress. Emotional (65.5\%) and physical (75.9\%) problems were the most reported, while only $3.4 \%$ reported having spiritual problems. As shown in Figure 2, worry (55.2\%), pain (37.9\%), nervousness (34.5\%), financial (34.5\%), sadness $(31.0 \%)$, fatigue (31.0\%), tingling in hands/feet $(27.6 \%)$ and work $(20.7 \%)$ were the most indicated. However, only $6.9 \%$ of patients reported moderate to severe symptoms of anxiety, and $6.9 \%$ reported symptoms of depression. In the quality of life scale (FACT-G), patients reported a mean score of $93.6(S D=18.8)$. Emotional well-being subscale $(M=20.5, S D=4.6)$ obtained the lowest average score when compared to other subscales. Regarding cognitive impairments (FACT-Cog), the overall mean score was 129.1 ( $S D=30.8)$; perceived cognitive impairments $(M=64.8, S D=2.0)$ and perceived cognitive abilities $(M=31.2, S D=7.3)$ presented worse results (Table 2$)$.

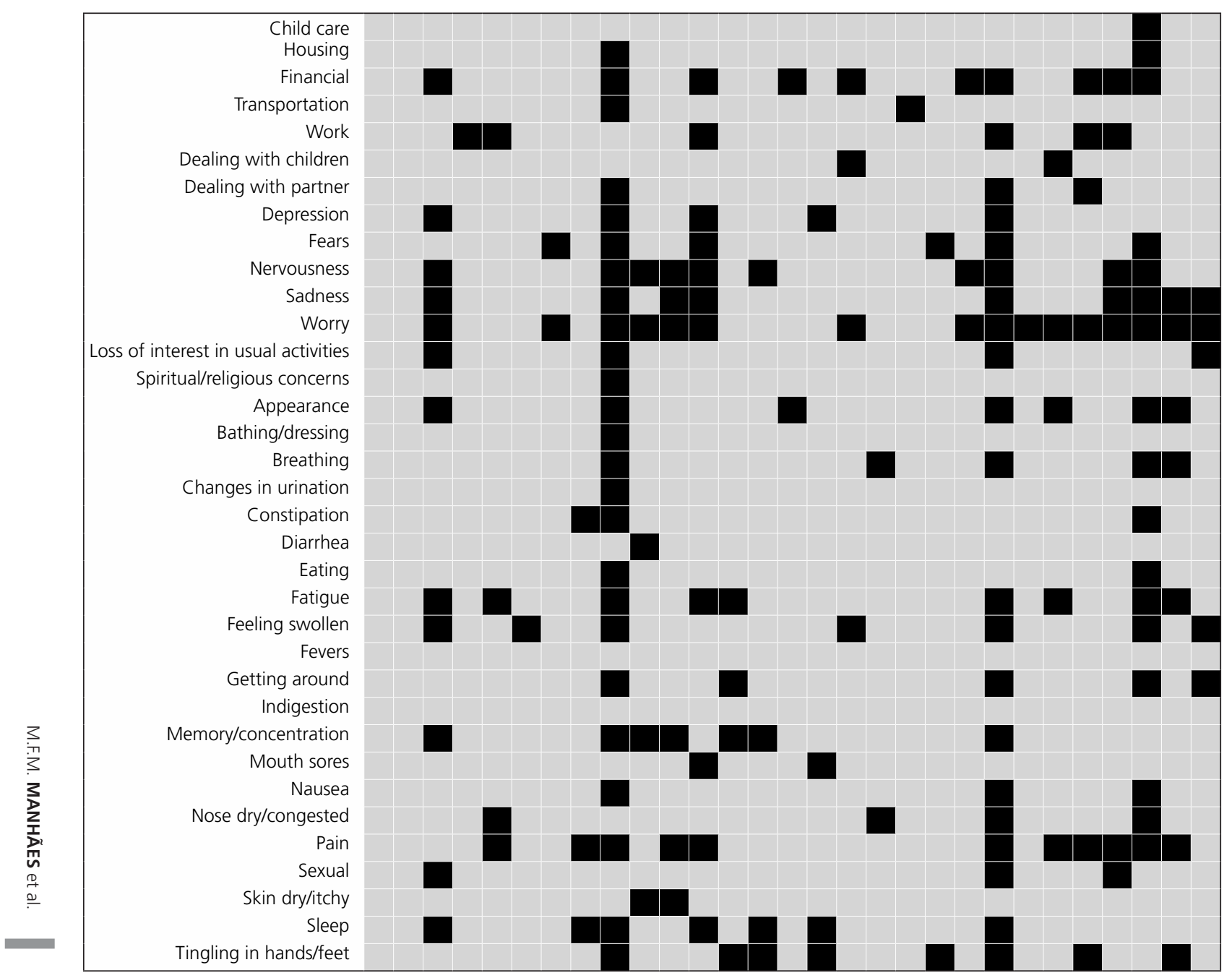

8 Figure 2. Tile Plot of the problem list on the Distress Thermometer. 
Descriptive analysis of distress (DT), anxiety and depression (HADS), quality of life (FACT-G), and cognitive impairments (FACT-COG) measures

\begin{tabular}{lcccc}
\hline \multicolumn{1}{c}{ Measures } & $M$ & & $S D$ & $(\mathrm{~min}-\mathrm{max})$ \\
\hline Distress Thermometer & 3.2 & \pm & 2.8 & $(0-10)$ \\
HADS - Anxiety & 3.2 & \pm & 3.8 & $(0-17)$ \\
HADS - Depression & 1.8 & \pm & 3.7 & $(0-15)$ \\
FACT-G & 93.6 & \pm & 18.8 & $(31-108)$ \\
Physical Well-Being & 24.0 & \pm .9 & $(4-28)$ \\
Social/Family Well-Being & 25.4 & \pm .3 & $(12-28)$ \\
Emotional Well-Being & 20.5 & \pm & $(6-24)$ \\
Functional Well-Being & 23.9 & \pm & $(7-28)$ \\
FACT-COG & 129.1 & \pm & 30.8 & $(41-148)$ \\
Perceived Cognitive Impairments & 64.8 & \pm & 23.5 & $(4-80)$ \\
Comments from others & 15.0 & \pm & 2.0 & $(8-16)$ \\
Perceived Cognitive Abilities & 31.2 & \pm & 7.3 & $(9-36)$ \\
Impact on Quality of Life & 14.9 & \pm & 2.7 & $(7-16)$ \\
\hline
\end{tabular}

When assessing specific needs of patient with testicular cancer, the items frequently low scored were: "I control my emotions by not expressing my feelings" (53.6\%), "I feel good about the way my body looks" (50.0\%), "I have been bothered by my physical health" (42.9\%), "I attemped to avoid feeling difficult emotions" (42.9\%), "I have mood swings" (39.3\%), "I am comfortable with my body" (35.7\%), "I do not have adequate confidence about sex" (32.1\%), "I am satisfied with my ability to have biological children" (28.6\%), "I get taken over by feelings of sadness or hopelessness" (28.6\%), "I am satisfied with my ability to ejaculate" (25.0\%), "I am able to talk with my partner about sex" (25.0\%), "I am satisfied with my ability to achieve orgasm" (25.0\%), "I don't tell people about cancer to avoid them showing pity for me" (25.0\%) and "I have been bothered by sex-related concerns" (25.0\%). On this scale, the mean score was $49.7(S D=9.7)$.

\section{Evidence of validation of the CAYA-T12 brief scale}

In the psychometric analysis of CAYA-T, a substantial factorial loading was observed in 12 of the 29 items selected to compose this scale, indicating evidence and validity of the construct. The excluded items obtained a low reliability coefficient (less than 0.32). The sample adequacy KMO test was 0.71 (sampling is middling adequate) and the Bartlett sphericity test was significant $(p=0.001)$, indicating that this factorial correlation does not reflect a matrix identity and attests the viability of the factorial analysis. The scree-plot highlighted three factors - Sexual Confidence and Functioning, Cognitive-Emotional Regulation and Specific Sexual Functioning - that explain $72 \%$ of the variance in response to the item (Table 3 ). The internal consistency was acceptable and the average inter-item correlation varied from 0.73 to 0.62 . The reliability coefficients were high, ranging from 0.95 to 0.90 . The results of the factorial analysis provided positive evidence regarding the validity of the construct.

In view of the new brief version of the CAYA-T (CAYA-T12), a significant correlation was found between distress, anxiety and depression, quality of life and cognitive impairments $(p<0.01)$ scales. A lower score in CAYA-T12 was associated with symptoms of anxiety (HADS-A, $p=0.001$ ), of depression (HADS-D, $p=0.001)$ and distress (DT, $p=0.006)$. A higher score in CAYA-T12 was associated with better quality of life (FACT-G; $p=0.001$ ) and lower cognitive impairments (FACT-Cog; $p=0.001$ ). A similar result was found 
Factorial analysis of the Cancer Assessment for Young Adults-Testicular12 brief scale

\begin{tabular}{|c|c|c|c|}
\hline Items & 1 & 2 & 3 \\
\hline \multicolumn{4}{|l|}{ Sexual Confidence and Functioning (Lambda2 $=0.90$; average inter-item correlation $=0.73$ ) } \\
\hline SexFunc1 - I am satisfied with my ability to have biological children & 0.51 & & \\
\hline SexFunc3 - I am satisfied with my level of interest in sex & 0.99 & & \\
\hline SexFunc4 - I am satisfied with my ability to achieve orgasm & 0.65 & & \\
\hline SCon3 - Sexually, I don't feel normal & 0.80 & & \\
\hline \multicolumn{4}{|l|}{ Cognitive-Emotional Regulation (Lambda2 $=0.95$; average inter-item correlation $=0.70$ ) } \\
\hline CogEmor1 - I struggle to understand my feelings about cancer & & 0.89 & \\
\hline CogEmor2 - I control my emotions by not expressing my feelings & & 0.65 & \\
\hline CogEmor5 - I can't shake the thought that something is seriously wrong with me & & 0.85 & \\
\hline CogEmor6 - I get taken over by my feelings of sadness or hopelessness & & 0.57 & \\
\hline CogEmor7 - I have mood swings & & 0.57 & \\
\hline \multicolumn{4}{|l|}{ Specific Sexual Functioning (Lambda2 $=0.94$; average inter-item correlation $=0.62$ ) } \\
\hline SexFunc2 - I am satisfied with my ability to ejaculate & & & 0.75 \\
\hline SexFunc5 - I am satisfied with my ability to achieve an erection & & & 0.63 \\
\hline Dab3 - I am able to talk with my partner about sex & & & 0.50 \\
\hline
\end{tabular}

for the Cognitive-Emotional Regulation and Specific Sexual Functioning subscales. On the other hand, the Sexual Confidence and Functioning subscale was associated with symptoms of depression $(p=0.01)$, better quality of life $(p=0.04)$ and lower cognitive impairments $(p=0.002)$.

When assessing the discriminatory power of the CAYA-T12 subscales according to the level of distress, anxiety, depression, quality of life and cognitive impairments, it was verified that the subscales Sexual Confidence and Functioning $(B=-0.70, S E=0.33, p=0.04)$, Cognitive-Emotional Regulation $(B=-1.32$, $S E=0.26, p=0.001)$ and Specific Sexual Functioning $(B=-1.21, S E=0.57, p=0.04)$ were predictors of anxiety symptoms ( $R 2 N=61 \%)$. Cognitive-Emotional Regulation $(B=-1.14, S E=0.21, p=0.001)$ and Specific Sexual Functioning $(B=-1.38, S E=0.45, P=0.005)$ subscales were predictors of symptoms of depression $(R 2 N=74 \%)$, and Cognitive-Emotional Regulation subscale $(B=-0.63, S E=0.23, p=0.01)$ was predictor of distress $(R 2 \mathrm{~N}=37 \%)$. For quality of life, only the Cognitive-Emotional Regulation subscale $(B=3.96$, $S E=2.26, p=0.001)$ was predictor of higher score in the FACT-G $(R 2 N=72 \%)$. The predictive value obtained in each linear regression was expressive, ranging from $74 \%$ to $37 \%$. A higher predictive value was found for the associations between depression (HADS-D) and Cognitive-Emotional Regulation and Specific Sexual Functioning subscales, and between quality of life (FACT-G) and Cognitive-Emotional Regulation subscale.

\section{Discussion}

In the present study, biopsychosocial needs of survivors of testicular cancer were identified and described, favoring an adequate understanding about the specificities of each patient. The use of the CAYA-T12 brief scale with standardized questionnaires for patients with cancer, proved to be relevant and appropriate for clinical and research purposes. Notably, sexual functioning was associated with distress, symptoms of anxiety and depression, and poorer quality of life. These results reinforce other findings, suggesting that some aspects from diagnosis and treatment represent risk factors for adapting to changes imposed by this disease (Acquati et al., 2018; Rossen et al., 2012; Shen et al., 2016; Skoogh et al., 2011).

A large proportion of patients reported moderate to severe distress, close to the one described among patients with metastatic cancer (Azevedo, Zayat, Okuma, De Domenico, \& Bergerot, 2017; Mitchell et al., 2011) and higher than the one reported in a sample of Brazilian patients treated in private or public health care 
settings (Bergerot et al., 2016; Bergerot et al., 2017). This difference can be understood by the epidemiological characteristic of this disease (rare cancers), age group (young age is a risk factor), site of disease and treatment modalities (Acquati et al., 2018; Bergerot et al., 2018; Carpentier et al., 2011; Giese-Davis et al., 2012; Horick et al., 2017; Hoyt et al., 2013). But, also, by problems reported by these patients (e.g., pain, fatigue, worry and financial problems), suggesting a similar relevance to patients undergoing treatment, which requires extended psychosocial support (Jacobsen, Nipp, \& Ganz, 2017). However, focusing on assessing symptoms of anxiety and depression did not prove to be a relevant strategy in this sample. As predicted, few patients reported symptoms of anxiety and depression (Smith et al., 2018; Vehling et al., 2016), suggesting that a comprehensive assessment is necessary to identify specific needs such as, masculine identity, reproductive health, and body image (Hoyt et al., 2013; Rossen et al., 2012; Skoogh, Steineck, Johansson, Wilderang, \& Stierner, 2013; Smith et al., 2018).

In general, the quality of life of these patients was considered very good, equivalent to the $75^{\text {th }}$ percentile of the normative study (Brucker et al., 2005). Only the emotional subscale had lower scores, closer to the average observed in the American population with cancer (Brucker et al., 2005). An expected outcome for patients survivors, no longer exposed to treatment's side effects or even to disease's symptoms (Cappuccio et al., 2018; Rossen, Pedersen, Zachariae, \& von der Maase, 2009). The exception found in the emotional subscale confirms the psychological impact of testicular cancer and allows health care professionals to identify and propose new ways to better address unmet needs of these survivors. Despite the physical and functional well-being attested on the FACT-G scale, results obtained in the FACT-Cog scale indicated a cognitive impairments in the Perceived Cognitive Abilities and Perceived Cognitive Impairments subscales. This is a late and long-term side effect of chemotherapy related to verbal and visual learning, memory and attention, processing speed and executive functioning (Chovanec et al., 2018). Further studies should be performed in order to better understand these sequelae in young men who had testicular cancer.

The CAYA-T scale highlighted specific needs of these survivors of testicular cancer, being feasible to identify some conflicts associated with self-image, sexual functioning (confidence and sexual functioning), and emotional well-being. These findings are usually characterized by a tendency to focus on feelings of inadequacy and inferiority, introversion, behavioral inhibition, and sensitivity to rejection (Hoyt, McCann, Savone, Saigal, \& Stanton, 2015). Thus, even though there is a low prevalence of symptoms of anxiety and depression, there are specific needs that should be identified and better explored, requiring careful treatment planning and special attention. It is worth noting the probable chronicity of these needs, considering the average time of survival ( 67.5 months) of these patients. As this study does not have data about these needs over time, an additional investigation is required to understand the longitudinal trajectory of these problems.

The clinical relevance of this critical finding reinforces the usefulness of a comprehensive assessment to identify specific demands, promoting an opportunity to target and to develop a treatment plan, in order to help patient to better adapt and cope with changes imposed by the treatment and the illness. Therefore, due to the evidence of validation of CAYA-T12, verified in the psychometric analysis, this brief version is endorsed for Brazilian patients diagnosed with testicular cancer. This scale is effective in assessing three domains - Sexual Confidence and Functioning, Cognitive-Emotional Regulation and Specific Sexual Functioning - with the ability to identify other morbidities (e.g., anxiety, depression), or even to discriminate the impact of these needs on patients' well-being (e.g., quality of life). Based on these findings, it is possible to state the usefulness and validity of the CAYA-T12 brief scale for biopsychosocial assessment of patients' functionality, being also valuable for the whole care of these patients; a useful and easy scale.

Some limitations of this study need to be described and discussed, such as the small sample size, justified by the rarity of this disease. However, this limitation did not impair the psychometric analysis of the CAYA-T12 (second objective of this study). As described in the method section, the evidence of validation of 
this scale was obtained, strictly following the criteria described in the literature for a sample size lower than 50 participants. Another limitation is due to the fact that patients were recruited from a single institution, reinforcing the need for multicenter studies to attest and amplify the results described here. In addition, only patients who completed treatment were included, and further research is needed to assess the immediate and late sequelae of this diagnosis and treatment. The exclusion of patients with a psychiatric disorder should be reviewed, in order to better clarify if this disorder is due to the testicular cancer. If there is a relationship between both, a new assessment should be done with the CAYA-T12 to better guide the psychological treatment in a possible randomized study.

In summary, young survivors with testicular cancer have specific needs, not necessarily identified by global instruments. Symptoms of anxiety and depression, for example, were not indicators of biopsychosocial risk, with an underlying demand that must be better explored and identified. In turn, distress was a quick way for identifying patients' needs, but it requires a specific assessment of sexual functioning and cognitive-emotional regulation. In view of needs identified in this study and the evidence of validation of the CAYA-T12, it is believed that this study may contribute to provide better supportive care for these patients, assisting health care providers to develop a supportive care program for patients with testicular cancer.

\section{Contributors}

All authors make substantial contributions to conception and design, acquisition of data, analysis and interpretation of data, discussion of the results, in the conception and the design of the study, analysis and interpretation of the data. All authors participate in drafting the article revising it critically, and giving final approval of the version submitted and approved.

\section{References}

Abouassaly, R., Fossa, S. D., Giwercman, A., Kollmannberger, C., Motzer, R. J., Schmoll, H. J., \& Sternberg, C. N. (2011). Sequelae of treatment in long-term survivors of testis cancer. European Urology, 60, 516-526. http://dx.doi. org/10.1016/j.eururo.2011.05.055

Acquati, C., Zebrack, B. J., Faul, A. C., Embry, L., Aguilar, C., Block, R., ... Cole, S. (2018). Sexual functioning among young adult cancer patients: A 2-year longitudinal study. Cancer, 124(2), 398-405. http://dx. doi.org/10.1002/cncr.31030

Arnold, B. J., Eremenco, S., Chang, C. H., Odom, L., Ribaudo, J., \& Cella, D. (2000). Development of a single Portuguese language version of the functional assessment of cancer therapy general (FACT-G) scale. Quality of Life Research, 9(3), 316.

Azevedo, I. M., Zayat, C. G., Okuma, G. Y., De Domenico, E. B. L., \& Bergerot, C. D. (2017). Sintomas biopsicossociais em pacientes com câncer incurável no Brasil. Brazilian Journal of Oncology, 13(45), 1-8. http://dx.doi.org/10.26790/ BJO20171345A92

Bergerot, C. D., Bergerot, P. G., Philip, E. J., De Domenico, E. B. L., Manhães, M. F. M., Pedras, R. N., ... Pal, S. K. (2018). Assessment of distress and quality of life in rare cancers. Psycho-Oncology, 27(12), 2740-2746. http://dx.doi. org/10.1002/pon.4873

Bergerot, C. D., Philip, E. J., Zayat, C. G., Azevedo, I. M., Araujo, T. C. C. F., \& De Domenico, E. B. L. (2016). Investigating the two-tiered system of psychosocial cancer care in Brazil using a distress screening measure. Journal of Global Oncology, 3(1), 1-6. http://dx.doi.org/10.1200/JGO.2016.004978

Bergerot, C. D., Zayat, C. G., Azevedo, I. M., Okuma, G. Y., Pedras, R. N., Marcusso, M. F. M., \& De Domenico, E. B. L. (2017). Implementação de programa de psico-oncologia segundo recomendações internacionais aplicadas em serviço público brasileiro. Estudos de Psicologia (Natal), 22(4), 350-357. http://dx.doi.org/10.22491/1678-4669.20170036

Botega, N. J., Bio, M. R., Zomignani, M. A., Garcia Jr., C., \& Pereira, W. A. (1995). Transtorno de humor em enfermaria de clínica médica e validação de escala de medida (HAD) de ansiedade e depressão. Revista de Saúde Pública, 29(5), 355-363. http://dx.doi.org/10.1590/S0034-89101995000500004 
Brucker, P. S., Yost, K., Cashy, J., Webster, K., \& Cella, D. (2005). General population and cancer patient norms for the Functional Assessment of Cancer Therapy-General (FACT-G). Evaluation \& the Health Professions, 28(2), 192-211. http://dx.doi.org/10.1177/0163278705275341

Cappuccio, F., Rossetti, S., Cavaliere, C., Iovane, G., Taibi, R., D'Aniello, C., ... Facchini, G. (2018). Health-related quality of life and psychosocial implications in testicular cancer survivors: A literature review. European Review for Medical and Pharmacological Sciences, 22(3), 645-661. http://dx.doi.org/10.26355/eurrev_201802_14290

Carpentier, M. Y., Fortenberry, J. D., Ott, M. A., Brames, M. J., \& Einhorn, L. H. (2011). Perceptions of masculinity and self-image in adolescent and young adult testicular cancer survivors: Implications for romantic and sexual relationship. Psycho-Oncology, 20(7), 738-745. http://dx.doi.org/10.1002/pon.1772

Chovanec, M., Vasilkova, L., Setteyova, L., Obertova, J., Palacka, P., Rejlekova, K., ... Mego, M. (2018). Long-term cognitive functioning in testicular germ-cell tumor survivors. The Oncologist, 23, 1-7. http://dx.doi.org/10.1634/ theoncologist.2017-0457

Decat, C. S., Laros, J. A., \& Araujo, T. C. C. F. (2009). Termômetro de distress: validação de um instrumento breve para avaliação diagnóstica de pacientes oncológicos. Psico-USF, 14(3), 253-260. http://dx.doi.org/10.1590/S141382712009000300002

Fossa, S. D., de Wit, R., Roberts, J. T., Wilkinson, P. M, de Mulder, P. H., Mead, G. M., ... Collete, L. (2003). Quality of life in good prognosis patients with metastatic germ cell cancer: A prospective study of the European Organization for Research and Treatment of Cancer Genitourinary Group/Medical Research Council Testicular Cancer Study Group (30941/TE20). Journal of Clinical Oncology, 21(6), 1107-1118. http://dx.doi.org/10.1200/JCO.2003.02.075

Giese-Davis, J., Waller, A., Carlson, L. E., Groff, S., Zhong, L., Neri, E., ... Bultz, B. D. (2012). Screening for distress, the 6th vital sign: Common problems in cancer outpatients over one year in usual care: Associations with marital status, sex, and age. BioMed Central Cancer, 12, 441-452. http://dx.doi.org/10.1186/1471-2407-12-441

Holland, J. C., Andersen, B., Breitbart, W. S., Buchmann, L. O., Compas, B., Deshields, T. L., ... Greiner, C. B. (2013). Distress management. Journal of the National Comprehensive Cancer Network, 11(2), 190-209.

Horick, N. K., Manful, A., Lowery, J., Domchek, S., Moorman, P., Griffin, C., ... Finkelstein, D. M. (2017). Physical and psychological health in rare cancer survivors. Journal of Cancer Survivor, 11(1), 158-165. http://dx.doi.org/10.1007/ s11764-016-0573-0

Hoyt, M. A., Cano, S. J., Saigal, C. S., \& Stanton, A. L. (2013). Health-related quality of life in young men with testicular cancer: Validation of the Cancer Assessment for Young Adults (CAYA). Journal of Cancer Survivors, 7(4), 630-640. http://dx.doi.org/10.1007/s11764-013-0302-x

Hoyt, M. A., McCann, C., Savone, M., Saigal, C. S., \& Stanton, A. L. (2015). Interpersonal sensitivity and sexual functioning in young men with testicular cancer: The moderating role of coping. International Journal of Behavioral Medicine, 22(6), 709-716. http://dx.doi.org/10.1007/s12529-015-9472-4

Jacobsen, P. B., Nipp, R. D., \& Ganz, P. A. (2017). Addressing the survivorship care needs of patients receiving extended cancer treatment. American Society of Clinical Oncology Educational Book, 37, 674-683. http://dx.doi.org/10.14694/ EDBK_175673

Mitchell, A. J., Chan, M., Bhatti, H., Halton, M., Grassi, L., Johansen, C., \& Meader, N. (2011). Prevalence of depression, anxiety, and adjustment disorder in oncological, haematological, and palliative-care settings: A meta-analysis of 94 interview-based studies. Lancet Oncology, 12(2), 160-174. http://dx.doi.org/10.1016/S1470-2045(11)70002-X

National Comprehensive Cancer Center. (2018). Testicular cancer: Version 2. Retrieved January 10, 2018, from http:// www.nccn.org/professionals/physician_gls/pdf/testicular_blocks.pdf

Rossen P. B., Pedersen, A. F., Zachariae, R., \& von der Maase, H. (2009). Health-related quality of life in long-term survivors of testicular cancer. Journal of Clinical Oncology, 27(35), 5993-5999. http://dx. doi.org/10.1200/JCO.2008.19.6931

Rossen, P., Pedersen, A. F., Zachariae, R., \& von der Maase, H. (2012). Sexuality and body image in long-term survivors of testicular cancer. European Journal of Cancer, 48(4), 571-578. http://dx.doi.org/10.1016/j.ejca.2011.11.029

Shen, A. H., Howell, D., Edwards, E., Warde, P., Matthew, A., \& Jones, J. M. (2016). The experience of patients with early-stage testicular cancer during the transition from active treatment to follow-up surveillance. Urologic Oncology, 34(4), 11-20. http://dx.doi.org/10.1016/j.urolonc.2015.09.016

Skoogh, J., Steineck, G., Cavallin-Ståhl, E., Wilderäng, U., Håkansson, U. K., Johansson, B., \& Stierner, U. (2011). Feelings of loss and uneasiness or shame after removal of a testicle by orchiectomy: A population-based long-term follow-up of testicular cancer survivors. International Journal of Andrology, 34(2), 183-192. http://dx.doi.org/10.1111/j.13652605.2010.01073.x 
Skoogh, J., Steineck, G., Johansson, B., Wilderang, U., \& Stierner, U. (2013). Psychological needs when diagnosed with testicular cancer: Findings from a population-based study with long-term follow-up. British Journal of Urology International, 111(8), 1287-1293. http://dx.doi.org/10.1111/j.1464-410X.2012.11696.x

Smith, A. B., King, M., Butow, P., Luckett, T., Grimison, P., Tones, G. C., ... Oliver, I. (2013). The prevalence and correlates of supportive care needs in testicular cancer survivors: A cross-sectional study. Psycho-Oncology, 22(11), 2557-2564. http://dx.doi.org/10.1002/pon.3323

Smith, A. B., Rutherford, C., Butow, P., Olver, I., Luckett, T., Grimison, P., ... King, M. (2018). A systematic review of quantitative observational studies investigating psychosocial distress in testicular cancer survivors. Psycho-Oncology, 27(4), 1129-1137. http://dx.doi.org/10.1002/pon.4596

Ten Berge, J. M. F., \& Zegers, F. E. (1978). A series of lower bounds to the reliability of a test. Psychometrika, 43(4), 575579. http://dx.doi.org/10.1007/BF02293815

Travis, L. B., Beard, C., Allan, J. M., Dahl, A. A., Feldman, D. R., Oldenburg, J., ... Fossa, S. D. (2010). Testicular cancer: Research strategies and recommendations. Journal of National Cancer Institute, 102(15), 1114-1130. http://dx.doi. org/10.1093/jnci/djq216

Vehling, S., Mehnert, A., Hartmann, M., Oing, C., Bokemeyer, C., \& Oechsle, K. (2016). Anxiety and depression in long-term testicular germ cell tumor survivors. General Hospital Psychiatry, 38, 21-25. http://dx.doi.org/10.1016/j. genhosppsych.2015.09.001

Wagner, L. I., Sweet, J., Butt, Z., Lai, J., \& Cella, D. (2009). Measuring patient self-reported cognitive function: Development of the functional assessment of cancer therapy-cognitive function instrument. The Journal of Supportive Oncology, 7(6), W32-W39.

Winter, J. C. F., Dodou, D., \& Wieringa, P. A. (2009). Exploratory factor analysis with small sample sizes. Multivariate Behavioral Research, 44(2), 147-181. http://dx.doi.org/10.1080/00273170902794206

Received: June 28, 2018

Final version: November 21, 2018

Approved: December 11, 2018 